\title{
Eosinophilic cystitis with recurrent urinary retention: case report
}

This article was published in the following Dove Press journal:

Research and Reports in Urology

22 March 2017

Number of times this article has been viewed

\section{Hongzoo Park}

Department of Urology, Kangwon National University Hospital, Kangwon National University School of Medicine, Chuncheon, South Korea
Correspondence: Hongzoo Park Department of Urology, Kangwon National University Hospital, I56 Baengnyeong-ro, Chuncheon 200-722, South Korea

Tel +82 332589478

Fax +82332582455

Email amcmd@daum.net

\begin{abstract}
Eosinophilic cystitis is a rare inflammatory disease of the bladder whose origin, pathogenesis, and treatment are unknown. Frequency, dysuria, and hematuria are frequent symptoms. Here, we report a rare occurrence of recurrent urinary retention and repetitive catheterization. A 67-year-old male presented with acute urinary retention and intermittent gross hematuria of 2 weeks duration. Urethral catheterization followed by a trial without catheter, was successful. Complete blood count showed presence of eosinophils (eosinophilia) and computed tomography of kidneys, ureter and bladder with contrast showed thickened bladder wall and small prostate. Cystoscopy revealed an erythematous lesion over the anterior wall. The rest of the mucosa was normal. Transurethral biopsies of the lesion were performed and histologic examination showed features of eosinophilic cystitis. Despite multiple medication regimens containing corticosteroids and antihistamines, he presented with recurrent urinary retention, approximately once every month. After 6 months, he was started on bethanechol, which led to no catheterization for up to 2 years. To the best of our knowledge, this is the first report on the successful use of bethanechol as a treatment for eosinophilic cystitis with recurrent urinary retention.
\end{abstract}

Keywords: eosinophilic cystitis, urinary bladder, bethanechol, urinary retention

\section{Introduction}

First described in 1960 by Brown, eosinophilic cystitis (EC) is a rare bladder disease. ${ }^{1}$ The histopathologic diagnosis includes transmural inflammation of the bladder, predominantly with eosinophilia. ${ }^{2}$ Clinical manifestation is commonly marked by urinary frequency, dysuria, urgency, hematuria, and suprapubic pain. Less frequent manifestations include urinary retention, gastrointestinal symptoms, incontinence, fever, skin rash, pneumaturia, and nocturnal enuresis. Patients with EC often have symptoms and clinical findings common to other urologic disorders, such as urinary tract infection, malignancy, and lower urinary symptoms. ${ }^{3}$ Although the etiology of the disease is unclear, allergies or bladder wall injury appear to be present in most cases. ${ }^{4}$ No treatment consensus exists, but usually effective treatments include steroids and antihistamines. $^{2}$ To the best of our knowledge, this is the first report of a rare EC patient presenting recurrent urinary retention, not controlled by steroids or antihistamines, but effectively treated by bethanechol.

\section{Case presentation}

The case review was conducted according to all guidelines outlined in the Declaration of Helsinki. Written informed consent for publication of this case report was obtained submit your manuscript | www.dovepress.com
Research and Reports in Urology 2017:9 51-53

(c) (i) (5) 2017 Park. This work is published and licensed by Dove Medical Press Limited. The full terms of this license are available at https://www.dovepress.com/terms. BY NG php and incorporate the Creative Commons Attribution - Non Commercial (unported, v3.0) License (http://creativecommons.org/licenses/by-nd/3.0/). By accessing the work you hereby accept the Terms. Non-commercial uses of the work are permitted without any further permission from Dove Medical Press Limited, provided the work is properly attributed. For permission for commercial use of this work, please see paragraphs 4.2 and 5 of our Terms (https://www.dovepress.com/terms.php). 
from the patient. A previously healthy 67 -year-old male was referred to our department, complaining of acute urinary retention and intermittent gross hematuria of 2 weeks duration. This was his first occurrence of a urologic problem. He had no history of bronchial asthma, hypertension, diabetes mellitus, or drug allergy. His general physical examination was unremarkable. A routine hematologic examination showed peripheral eosinophilia (10\%). His biochemical profile was within normal limits. Analysis of midstream urine showed red blood cells 25-30/high-power field (HBF) white blood cells 10-15/HPF, and presence of few epithelial cells. Urine culture showed no growth. He was treated with antibiotics and insertion of urinary catheter. Computed tomography (CT) urography showed thickened anterior bladder wall and a small prostate. Cystoscopy revealed an erythematous mucosal lesion over the anterior wall, with no evidence of prostatic obstruction (Figure 1). Cold-cup biopsies showed diffuse infiltration of mucosa by eosinophils (Figure 2). Immunohistochemical examination of the specimen obtained by cystoscopy revealed CD44 staining in the entire thickness of the urothelium (Figure 3).

Urethral catheterization for 3 days, followed by a trial without catheter (TWOC), was successful. The patient was given a combination of oral prednisone taper $(30,20$, and $10 \mathrm{mg})$

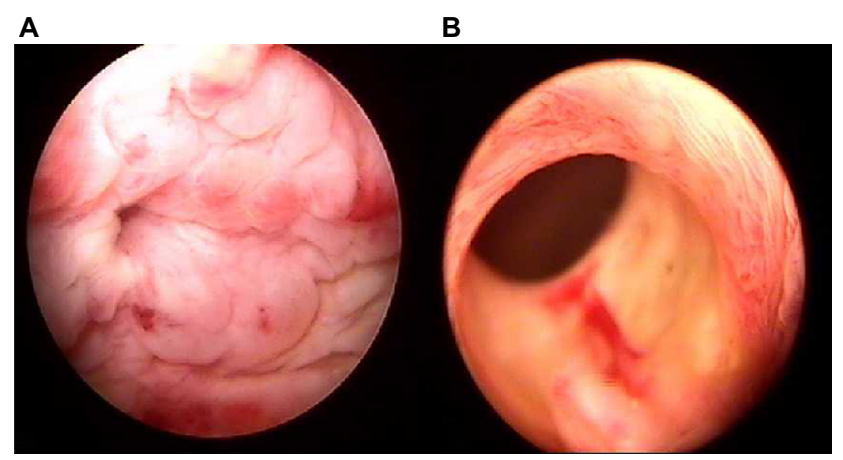

Figure I Cystoscopy revealed an erythematous mucosal lesion over the anterior wall and a small prostate.

Notes: (A) Anterior wall of bladder. (B) Prostatic urethra.

A

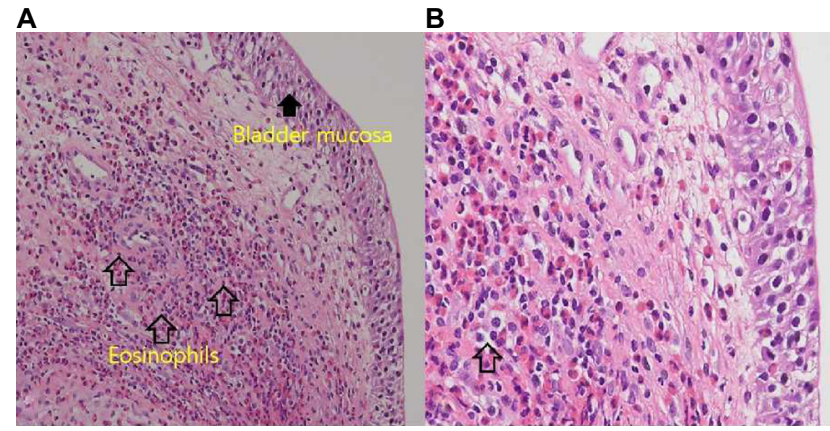

Figure 2 Histopathologic examination of the specimen obtained by cystoscopy showed infiltration of the bladder submucosa by numerous eosinophils. Notes: Hematoxylin and eosin staining, $\times 200$ (A) and $\times 400$ (B).

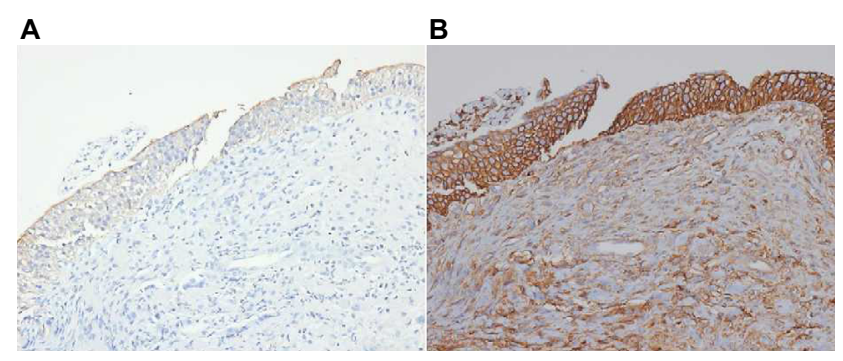

Figure 3 Immunohistochemical examination of the specimen obtained by cystoscopy.

Notes: (A) Staining limited to the superficial cell layer for Cytokeratin 20; $\times 200$. (B) staining in full thickness of the urothelium for CD44; $\times 200$.

with the dose reduced every 5 days, and oral hydroxyzine 30 $\mathrm{mg}$ three times daily. Urodynamic study proved no evidence of detrusor underactivity or lower urinary tract obstruction. There were no episodes of hematuria from then on. However, he visited our emergency room due to urinary retention after 1 month. Second urethral catheterization followed by a TWOC was successful. Second cystoscopy revealed the disappearance of the previous abnormal mucosal lesion. His prednisone dose was increased to $40 \mathrm{mg}$ for 6 months, due to recurrent retention episodes occurring approximately once a month. Bethanechol $50 \mathrm{mg}$ was added after the seventh relapsing episode of retention, which led to no catheterization for up to 2 years. During this time, the dose of prednisone was reduced to $5 \mathrm{mg}$ daily and oral hydroxyzine was discontinued. Two years later, bethanechol alone was discontinued to confirm the effect of bethanechol on EC. He visited the emergency room due to acute urinary retention after 7 days. Bethanechol 50 $\mathrm{mg}$ was added after that, which led to no catheterization for up to 3 months. During this time, prednisone was discontinued.

\section{Discussion}

To our knowledge, this is the first case to document bethanechol as a treatment for $\mathrm{EC}$ in an adult patient with prednisone refractory recurrent urinary retention. His urodynamic study did not show any evidence of detrusor underactivity and urinary tract obstruction. However, he suffered from recurrent urinary retention.

Mosholt et al performed a literature search in PubMed from 2003 to 2013 using the search word "eosinophilic cystitis". ${ }^{3}$ They studied 56 cases of EC. The most common symptoms were frequency, dysuria and urgency, in 33 cases $(59 \%)$. Urinary retention was reported in six $(11 \%)$ cases; however, there were no reports of recurrent retention.

Due to the rarity, treatment of EC is not standardized, and treatment modalities as well as course of treatment varied throughout cases. ${ }^{2}$ Steroids and antihistamines were the most commonly used, but $\sim 20 \%$ of patients had symptoms 
refractory to two combination therapies. ${ }^{5-9}$ Various treatment options were tried to treat EC, such as nonsteroidal antiinflammatory drugs, ${ }^{10}$ spasmolytic drugs, ${ }^{11}$ alpha receptor blocker, ${ }^{12}$ cyclosporin, ${ }^{7}$ and even surgery. ${ }^{6}$

In the previous studies, the most obvious cause for recurrence was insufficient dose of steroids (early tapering). ${ }^{3}$ In light of this, we maintained and increased the prednisone dose. However, his symptom recurrence continued, which stopped only after we added on bethanechol. This drug is a parasympathomimetic choline carbamate that selectively stimulates muscarinic receptors without any effect on the nicotinic receptors. Bethanechol is administered in the treatment for urinary retention resulting from general anesthetics, diabetic neuropathy of the bladder, or a side effect of antidepressants. The muscarinic receptors in the bladder stimulate contraction of the bladder and expulsion of urine. The mechanism by which bethanechol helps to improve the symptoms of EC with recurrent retention, is not clear. One possible reasoning is that eosinophilic inflammation of EC results in the dysfunction of muscarinic receptors of bladder muscle.

In summary, we encountered a previously healthy man suffering recurrent urinary retention due to EC. His symptoms did not improve with prednisone, but were reduced by bethanechol. To the best of our knowledge, we are the first to report a rare EC patient presenting recurrent urinary retention, not controlled by steroids or antihistamines, but effectively treated by bethanechol.

\section{Disclosure}

The author reports no conflicts of interest in this work.

\section{References}

1. Brown EW. Eosinophilic granuloma of the bladder. J Urol. 1960;83: 665-668.

2. van den Ouden D. Diagnosis and management of eosinophilic cystitis: a pooled analysis of 135 cases. Eur Urol. 2000;37(4):386-394.

3. Mosholt KS, Dahl C, Azawi NH. Eosinophilic cystitis: three cases, and a review over 10 years. BMJ Case Rep. 2014;bcr2014205708.

4. Sparks S, Kaplan A, DeCambre M, Kaplan G, Holmes N. Eosinophilic cystitis in the pediatric population: a case series and review of the literature. J Pediatr Urol. 2013;9(6 Pt A):738-744.

5. Kumar S, Sharma V, Ganesamoni R, Singh S. Eosinophilic cystitis mimicking tuberculosis: an analysis of five cases with review of literature. Urol Ann. 2013;5(1):50-52.

6. Salman M, Al-Ansari AA, Talib RA, El Malik el F, Al-Bozaom IA, Shokeir AA. Eosinophilic cystitis simulating invasive bladder cancer: a real diagnostic challenge. Int Urol Nephrol. 2006;38(3-4) 545-548.

7. Barese CN, Podesta M, Litvak E, Villa M, Rivas EM. Recurrent eosinophilic cystitis in a child with chronic granulomatous disease. J Pediatr Hematol Oncol. 2004;26(3):209-212.

8. Chia D. Eosinophilic cystitis and haematuria: case report of a rare disease and common presentation. Int J Surg Case Rep. 2016;24: $43-45$.

9. Saadi A, Bouzouita A, Ayed H, et al. Pseudotumoral eosinophilic cystitis Urol Case Rep. 2015;3(3):65-67.

10. Caso J, Qin D, Sexton WJ. Eosinophilic cystitis following immediate post-resection intravesical instillation of mitomycin-C. Can J Urol. 2010;17(3):5223-5225.

11. Popescu OE, Landas SK, Haas GP. The spectrum of eosinophilic cystitis in males: case series and literature review. Archives of pathology \& laboratory medicine. 2009;133(2):289-294.

12. Tsakiri A, Balslev I, Klarskov P. Eosinophilic cystitis induced by penicillin. Int Urol Nephrol. 2004;36(2):159-161.
Research and Reports in Urology

\section{Publish your work in this journal}

Research and Reports in Urology is an international, peer-reviewed, open access journal publishing original research, reports, editorials, reviews and commentaries on all aspects of adult and pediatric urology in the clinic and laboratory including the following topics: Pathology, pathophysiology of urological disease; Investigation and treatment of

\section{Dovepress}

urological disease; Pharmacology of drugs used for the treatment of urological disease. The manuscript management system is completely online and includes a very quick and fair peer-review system, which is all easy to use. Visit http://www.dovepress.com/testimonials.php to read real quotes from published authors. 